\title{
RESENHAS RESENHAS RESENHAS RESENHAS
}

https://doi.org/10.1590/198053145994

\section{ÉTICA E PESQUISA EM EDUCAÇ̃̃O: UMA DISCUSSÃO NECESSÁRIA}

Maria de Lourdes Teixeira Barros'

Maria Inês Marcondes"

BROOKS, Rachel; TE RIELE, Kitty; MAGUIRE, Meg. Ética e pesquisa em educação. Tradução de Janete Bridon. Ponta Grossa: Editora UEPG, 2017.

O livro Ética e pesquisa em educação traz uma grande contribuição para a discussão que se iniciou no Brasil com as resoluções n. 196/1996 e n. 510/2016² do Conselho Nacional de Saúde (CNS). A primeira criou o sistema CEP/Conep (Comitê de Ética em Pesquisa/Comissão Nacional de Ética em Pesquisa), que passou a ser o meio para aprovação das pesquisas no Brasil, tanto na área biomédica como nas ciências humanas e sociais (CHS). Foi modificada em 2012, pela Resolução CNS n. 466, ${ }^{3}$ que instituiu a Plataforma Brasil (sistema eletrônico unificado de registro de pesquisas envolvendo seres humanos, vinculado ao Ministério da Saúde). Já a Resolução n. 510/2016, considerando as características específicas da pesquisa em CHS e fruto de debates intensos entre pesquisadores da educação, veio dispor sobre as normas aplicáveis a pesquisas que envolvam a utilização de dados obtidos diretamente com os participantes ou que possam acarretar riscos. Entretanto, o formulário da Plataforma Brasil, a ser preenchido pelo pesquisador, não fora revogado. Com isso, conforme Mainardes (2017), apesar de a ética ser uma preocupação constante dos pesquisadores em educação, o problema central vem sendo o caráter burocrático das resoluções no Brasil, com procedimentos uniformes para a pesquisa biomédica e em CHS, o que acaba por estabelecer um desencontro entre tais regras e as especificidades da pesquisa educacional. Assim, "os pesquisadores da área de educação têm mantido uma certa distância das questões da revisão ética, pelo menos dos procedimentos do sistema CEP/Conep” (MAINARDES, 2017, p. 161). O livro, em contraponto, imprime ao debate uma abordagem reflexiva, baseada na realidade da pesquisa e superando a noção de ética como um conjunto de normas e preenchimento de formulários. Nessa perspectiva, a finalidade da reflexão é levar os pesquisadores à avaliação

\footnotetext{
I Pontifícia Universidade Católica do Rio de Janeiro (PUC-Rio), Rio de Janeiro (RJ), Brasil; http://orcid.org/0000-0003-1593-7018; lourdestbarros@gmail.com

II Pontifícia Universidade Católica do Rio de Janeiro (PUC-Rio), Rio de Janeiro (RJ), Brasil; http://orcid.org/0000-0002-0973-9405; mim@puc-rio.br

1 Disponivel em: http://bvsms.saude.gov.br/bvs/saudelegis/cns/1996/resO196_10_10_1996.html. Acesso em: 20 jun. 2018

2 Disponível em: http://conselho.saude.gov.br/resolucoes/2016/reso510.pdf. Acesso em: 20 jun. 2018.

3 Disponível em: http://bvsms.saude.gov.br/bvs/saudelegis/cns/2013/res0466_12_12_2012.html. Acesso em: 20 jun. 2018
} 
para a tomada de decisões responsáveis em relação aos participantes da pesquisa, preservando seus direitos e interesses. As autoras são pesquisadoras educacionais com interesse na questão da ética reflexiva. Rachel Brooks é chefe do Departamento de Sociologia da Universidade de Surrey, no Reino Unido e, em 2013, coeditou com Kitty te Riele o livro Negotiating ethical challenges in youth research, da editora Routledge. Kitty te Riele é pesquisadora chefe no Instituto Victoria de Educação, Diversidade e Aprendizagem ao longo da vida, na Universidade de Victoria, na Austrália. Ela ensina ética profissional para docentes em formação e atua em comitês de ética em pesquisa. Meg Maguire, professora de Sociologia da Educação no Departamento de Educação e Estudos Profissionais do King’s College, em Londres, atua na área de política educacional e supervisiona pesquisas em cursos de pós-graduação em estudos educacionais. O livro foi traduzido por Janete Bridon, em uma iniciativa da Universidade Estadual de Ponta Grossa, sob coordenação editorial de Lucia Cortes da Costa e revisão da tradução de Jefferson Mainardes.

\section{A QUESTÃO DA ÉTICA NA PESQUISA EM EDUCAÇÃO: UMA PREOCUPAÇÃO CONSTANTE}

Trata-se de uma obra organizada em nove capítulos, propondo discussão e análise acerca de dilemas éticos que perpassam a pesquisa em educação. É defendido o argumento de que a ética deve ser uma preocupação constante do pesquisador, em qualquer das etapas de sua investigação, e são fornecidas discussões sobre a ética em diferentes espaços, métodos e cenários de pesquisa. A intenção é provocar reflexões na comunidade internacional de pesquisadores, em um contexto de pouca produção acerca do tema para o público específico de educadores que, muitas vezes, pesquisam em seu próprio local de trabalho e estão vinculados a questões políticas que podem favorecer ou dificultar o desenrolar de sua investigação.

Baseando-se em exemplos de dilemas éticos variados, oriundos de diferentes contextos educacionais e áreas geográficas, as autoras iniciam os capítulos com pequenos textos ilustrativos, construídos a partir das suas experiências, que funcionam como propostas para "estudos de caso". Cada capítulo desenrola-se abordando aspectos da questão ética apresentada, embora fique claro que a finalidade da obra não é fornecer respostas prontas a essas questões, mas sim proporcionar reflexões aos leitores e deflagrar o debate.

Há uma intenção de diferenciar-se de outros escritos sobre o tema, que, de um modo geral, abordam a questão da ética em uma etapa específica do processo de investigação, a coleta de dados. Dessa forma, os capítulos são estruturados no sentido de enfatizar uma abordagem cronológica das fases de pesquisa, tratando de premissas éticas que envolvem um projeto, desde o seu design inicial até a divulgação de resultados. No entanto, os capítulos podem ser lidos de forma não linear, sem prejuízo para a compreensão da obra.

Já na Introdução, as autoras discutem a importância da temática para os pesquisadores e justificam a escolha por manter o foco da reflexão na área educacional. Em seguida, são enunciados diferentes métodos de pesquisa que serão 
trazidos ao longo dos capítulos e demonstra-se como a questão ética pode variar no tempo e no espaço.

O capítulo 2, “Teorias éticas, princípios e orientações”, traz uma breve abordagem das principais teorias filosóficas sobre a ética: utilitarismo, deontologia e ética da virtude. Apresenta-se uma visão geral dos códigos de ética e princípios em pesquisa, com destaque para o relatório Belmont e a Bera (2011). São examinadas, de forma crítica, as orientações e suas formas de implementação pelos Comitês de Ética em Pesquisas.

O capítulo seguinte, "Contextos regulatórios", faz uma análise da Convenção das Nações Unidas sobre os Direitos da Criança (CNUDC), adotada em 1989, que estabelece padrões como instrumento jurídico vinculado aos direitos humanos, e, segundo as autoras, fundamental para a pesquisa envolvendo crianças. Destacam-se regulamentações e legislação de Austrália, Canadá, Reino Unido, Estados Unidos e Nova Zelândia.

O enfoque dado no capítulo “Design da pesquisa” refere-se às questões éticas pertinentes à escolha do tópico, dos métodos e dos locais da pesquisa, ou seja, do design inicial, com a ressalva de que algumas dessas decisões ocorrerão no decorrer da investigação, não sendo possível completa antecipação dos dilemas éticos. O texto possibilita a reflexão sobre a pesquisa como um ato político, o que está diretamente relacionado à escolha de tópico e métodos e à tomada de posição do pesquisador. São abordadas as questões que podem estar presentes nessas escolhas, em especial quando se trata de pesquisas patrocinadas ou encomendadas.

"Consentimento esclarecido e reciprocidade" é o título do capítulo que aponta, além do conceito de "consentimento esclarecido", diversos questionamentos que permeiam essa tomada de decisão. As autoras escolheram três métodos de pesquisa para ilustrar tais questões: etnografia, pesquisa-ação e pesquisa em espaços virtuais. A maneira como os participantes são informados quanto aos objetivos e procedimentos da pesquisa também é um aspecto abordado no capítulo, englobando a discussão sobre a limitação de revelações aos sujeitos participantes e o oferecimento de reciprocidade, como incentivos financeiros, aconselhamentos e convites para que estes se envolvam plenamente no projeto de pesquisa. Em todos esses casos, é feita uma abordagem apontando defesas e críticas aos métodos. As autoras destacam como as relações de poder nas instituições podem ter influência sobre o processo de consentimento esclarecido.

A complexidade da questão ética é tratada no capítulo 6, "Identidade, poder e posicionamento", incluindo as relações entre pesquisador e pesquisado, com o argumento de que deve ser permanente a negociação entre as partes e que o posicionamento do pesquisador pode alterar a dinâmica da pesquisa, assim como sua compreensão da posição de cada participante. O capítulo explora algumas especificidades dessas relações, como nos casos de pesquisa com minorias, comunidades marginalizadas, crianças e com colegas do ambiente de trabalho. Como destaque, têm-se as considerações acerca da pesquisa com crianças, em relação a acesso, consentimento e relação de poder, assim como no que se refere ao respeito que deve ser estabelecido em uma abordagem ética, reconhecendo suas 
competências e capacidades como participantes da pesquisa. Questões sobre confidencialidade e privacidade aparecem como centrais e toda a discussão parte de situações selecionadas como exemplos. Este capítulo traz uma reflexão aprofundada sobre diferentes aspectos que envolvem pesquisadores que compartilham experiências com os grupos pesquisados. Discutem-se, por exemplo, os méritos e os limites da pesquisa com grupos minoritários quando realizada por seus pares, indo ao encontro do debate, bastante atual, sobre quem está ou não autorizado a fazer pesquisa com determinados grupos. Conclui-se que o pesquisador ético deve constantemente, e de forma consistente, refletir sobre como conduzir sua pesquisa, fazendo, em sua prática, escolhas moralmente boas.

O capítulo seguinte, “Análise de dados”, traça a importância do cuidado do pesquisador para que os dados não sejam utilizados de forma tendenciosa, como apoio ou crítica ao que se deseja evidenciar. É mencionado como achados de pesquisa quantitativa podem ser interpretados de diferentes modos, de acordo com a narrativa do pesquisador ou dos formuladores de política. Frisa-se que a omissão ou o exagero no relato dos dados também é um problema que pode assumir relevância como fator de alteração nos resultados da investigação. Analisando situações recorrentes em pesquisas qualitativas, as autoras indicam que os problemas geralmente aparecem na etapa de seleção de dados, quando estes precisam ser reduzidos para a análise. Por fim, elas consideram que uma das mais complexas questões éticas diz respeito às crenças e aos valores do pesquisador, quando o posicionamento ou a conveniência política pode levar à busca, em seus dados, por afirmações de seu ponto de vista. O argumento defendido é o de que, por razões éticas, os pesquisadores precisam aplicar técnicas investigativas rigorosas, abordagem sistemática em relação aos processos de codificação e análise e demonstrar claras evidências dos achados da pesquisa.

O capítulo 8, "Disseminação", destaca a importância da abordagem da ética nos momentos de disseminação das informações, tanto daquelas obtidas durante o processo de pesquisa quanto das que fazem parte de seus resultados, considerando o registro escrito, a divulgação oral e o retorno aos participantes. Ao abordar esse tema, as autoras iluminam uma questão muitas vezes não reconhecida, mas que se apresenta como um grande desafio ético.

Por fim, nas "Conclusões”, as autoras apresentam seus principais argumentos, consideram as lacunas no trabalho e fazem recomendações para o debate da ética na pesquisa. Apontam, como limites para a execução da obra, a utilização exclusiva de textos em língua inglesa e o fato de não terem abordado de forma mais aprofundada algumas questões, como a análise filosófica de valores sociais e morais que regulam as relações éticas na pesquisa social, alguns dos procedimentos de pesquisa e o complexo debate ético sobre o trabalho com grupos que são socialmente ou culturalmente marginalizados. Elas indicam, como uma das considerações finais, que não há respostas óbvias sobre os dilemas éticos com os quais o pesquisador irá se deparar no curso de seu processo de pesquisa, sendo esse um dos maiores desafios para que se chegue a uma decisão ética, visto que não há códigos de comportamento a serem seguidos. Para as autoras, as decisões derivam de valores morais e de diferentes pontos de vista, os quais podem se 
modificar no espaço e no tempo, mas um pesquisador responsável deve estar receptivo a revisitar esse conjunto de valores à medida que o trabalho avança.

\section{O LIVRO E SEU CONTEÚDO: O QUE TRAZ DE NOVO PARA A DISCUSSÃO}

Essa obra oferece um texto de leitura fundamental para os pesquisadores que trabalham com interações humanas. Mostra-se de grande relevância por abordar as pesquisas em educação que envolvem crianças, visto que esse tema não costuma ser diretamente cuidado em textos desse teor. Destaca-se também a apresentação de contexto jurídico, problematizando as diferenças da legislação entre países.

Os capítulos têm uma breve apresentação do tema a ser tratado, o que é bom para situar o leitor no texto e ajudá-lo a selecionar o momento de maior interesse para sua leitura. Da mesma forma, sempre terminam com uma conclusão do que foi abordado, ajudando a organizar uma síntese de ideias e apontando destaques. $\mathrm{O}$ capítulo 6 apresenta um diferencial bastante positivo em relação a textos similares, quando as autoras discutem a ética no posicionamento do pesquisador na sua prática de pesquisa, para além da preocupação com o texto escrito e com formulários de consentimentos, destacando situações e tensões inesperadas que acontecem no cotidiano das investigações, tratadas de forma direta e ilustrada. É interessante a estrutura do texto, com a busca constante pela síntese e a motivação ao leitor com os casos trazidos para reflexão. A obra tem o grande mérito de propor discussões ainda pouco abordadas na pesquisa em educação, fazendo isso de forma direta e propositiva.

Ética e pesquisa em educação traz contribuições valorosas aos pesquisadores da área da educação e a todos aqueles que se dedicam ao estudo de metodologia de pesquisa, deparando-se frequentemente com dilemas éticos no percurso das investigações. Devido à relevância temática e abordagem única, torna-se leitura primordial nos ambientes de pesquisa.

\section{REFERÊNCIAS}

BRITISH EDUCATIONAL RESEARCH ASSOCIATION (BERA). Ethical guidelines for educational research. London: Bera, 2011.

BROOKS, Rachel; TE RIELE, Kitty; MAGUIRE, Meg. Ética e pesquisa em educação. Tradução de Janete Bridon. Ponta Grossa: Editora UEPG, 2017.

MAINARDES, Jefferson. A ética na pesquisa em educação: panorama e desafios pós-Resolução CNS n. 510/2016. Educação, Porto Alegre, v. 40, n. 2, p. 160-173, maio/ago. 2017.

\section{COMO CITAR ESTA RESENHA:}

BARROS, Maria de Lourdes Teixeira; MARCONDES, Maria Inês. Ética e pesquisa em educação: uma discussão necessária. Cadernos de Pesquisa, São Paulo, v. 49, n. 171, p. 332-337, jan./mar. 2019. [Seção] Resenhas. Resenha da obra de: BROOKS, Rachel; TE RIELE, Kitty; MAGUIRE, Meg. Ética e pesquisa em educação. Tradução de Janete Bridon. Ponta Grossa: Editora UEPG, 2017. https://doi.org/10.1590/198053145994 
